УДК 811.111-26

DOI 10.18413/2712-7451-2020-39-2-271-279

\title{
Стилистическое своеобразие эпитета в произведениях Дж. Д. Сэлинджера
}

\author{
Войтальянова Я.И., Шелихова С.В. \\ Сибирский государственный университет науки и технологий \\ имени академика М.Ф. Решетнёва, \\ Россия, 660037, г. Красноярск, просп. им. газ. «Красноярский рабочий», 31 \\ E-mail: shelihovasvetlana@.mail.ru
}

\begin{abstract}
Аннотация. Выявление стилистических своеобразия эпитета проведено через исследование особенностей прозы Дж. Д. Сэлинджера, что является новым в исследовании творчества автора. Эпитет рассматривается в контексте общей характеристики стиля данного автора и во взаимосвязи с другими средствами выражения эмоциональности (наречием, эмотивными словами). Доказано, что наличие большого количества эпитетов-наречий, свойственных разговорной разновидности литературного языка, помогает выражать высокую степень интенсивности признака и указывает на «живую», непридуманную речь. Проанализирована качественная и структурная характеристика эпитета, установлено, что воздействие эпитета возрастает, если он употребляется вместе с усилительным наречием, эмотивными словами, группой эпитетов, ставится в постпозицию. Выявлено, что структурное преобладание простого, составного эпитета и двуступенчатого эпитета объясняется содержательной характеристикой рассказов и стремлением автора передать разговорную речь, в которой необходимо просто и точно выражать свои мысли, соблюдая нормы литературного языка.
\end{abstract}

Ключевые слова: стиль, стилистика, эпитет-наречие, экспрессивность, эмоциональность.

Для цитирования: Войтальянова Я.И., Шелихова С.В. 2020. Стилистическое своеобразие эпитета в произведениях Дж.Д. Сэлинджера. Вопросы журналистики, педагогики, языкознания, 39 (2): 271-279. DOI 10.18413/2712-7451-2020-39-2-271-279

\section{Stylistic originality of the epithet In the works of J. D. Salinger}

\author{
Yanina I. Voytalyanova, Svetlana V. Shelikhova \\ Reshetnev Siberian State Aerospace University \\ 31 Krasnoyarsky Rabochy Av., Krasnoyarsk, 660037, Russian \\ E-mail: shelihovasvetlana@.mail.ru
}

\begin{abstract}
The identification of stylistic peculiarities of the epithet was carried out through the study of the features of J. D. Salinger's prose, which is new in the study of the author's creativity.The epithet is considered in the context of the general characteristic of the style of this author and in relation to other means of expressing emotionality (adverb, emotive words).The article proves that the presence of a large number of epithets-adverbs peculiar to the colloquial variety of literary language helps to express a high degree of intensity of the trait and indicates a «live» speech.The qualitative and structural characteristics of epithets are analyzed. It is found that the impact of an epithet increases if it is used together with an amplifying adverb, emotive words, a group of epithets, and is put in postposition. It is revealed that the structural predominance of a simple, composite epithet and a two-step epithet is explained by the content
\end{abstract}


characteristic of stories and the author's desire to convey colloquial speech, in which it is necessary to simply and accurately express their thoughts, observing the norms of the literary language.

Key words: style, stylistics, epithet-adverb, expressiveness, emotionality.

For citation: Voytalyanova Ya.I., Shelikhova S.V. 2020. Stylistic originality of the epithet in the works of J.D. Salinger. Issues in Journalism, Education, Linguistics, 39 (2): 271-279 (inRussian). DOI $10.18413 / 2712-7451-2020-39-2-271-279$

\section{Введение}

Дж. Д. Сэлинджер является выдающимся представителем современной американской литературы. В этом мнении едины практически все исследователи творчества Дж. Д. Сэлинджера [Галинская, 1986; Колесниченко, 2008; Штайн, 2016]. При этом ученые исследуют вопросы, связанные с философскими и эстетическими основами творчества Дж. Д. Сэлинджера [Jacquette, 2015; Галинская, 1986; Любимская, 2016], спецификой перевода произведений [Колесниченко, 2008; Д.И. Петренко, 2009], лексическими и стилистическими особенностями работ Дж. Д. Сэлинджера [Rostami, 2012; Липустина, Щелок, Виноградова, 2019; Тютина, 2015]. Цель исследования обусловлена не только интересом к творчеству знаменитого писателя, но и особенностями стилистики как науки, способствующей глубокому пониманию текста произведения, развивающей культуру эмоционального восприятия художественного текста и выявляющей лингвистическую значимость проблематики изучения отдельных ее аспектов.

Несмотря на большое количество исследований, посвящённых различным аспектам стилистических и лексических особенностей художественного произведения, сохраняется актуальность изучения отдельных компонентов, составляющих целостную структуру текста, поскольку каждый раз мы имеем дело с уникальным произведением, имеющим свой набор определенных и специфических авторских средств выразительности.

Разумеется, что эпитет не может быть рассмотрен в отрыве от других стилистических явлений и изолированно от общей характеристики стиля автора, поэтому возможно рассмотрение эпитета в связи с другими средствами выражения эмоциональности для составления более полной картины о стиле данного автора вообще и о своеобразии употребления эпитета в произведениях Дж. Д. Сэлинджера в частности.

Стилю речи героев Дж. Д. Сэлинджера присущи та особенность и уникальность, которые дают нам хорошую возможность составить представление о речевой характеристике всего поколения. В качестве основной темы произведений Дж. Д. Сэлинджера исследователи называют сложный переход из юности во взрослый мир, неизбежную смену ценностных ориентаций, которая сопровождает этот переход, отчаянное и безнадежное сопротивление, которое возникает при осознании неотвратимости такого шага [Зверев, 1997, с. 459]. Герои Дж. Д. Сэлинджера усиленно размышляют о других и о себе, об окружающем мире и о своих взаимоотношениях с ним. Отстраненность от общества и непохожесть на других говорит о сложной душевной организации главных героев произведений, о глубоком и тонком восприятии окружающей их действительности. Именно эпитет позволяет автору показать всю гамму эмоционально-обостренной напряженности восприятия мира, где, казалось бы, самая обычная незначительная ситуация вызывает чрезмерную, нарочито преувеличенную реакцию, сильнейший эмоциональный отзыв.

\section{Основная часть}

Вполне естественно, что особенности современной новеллы заключаются не только в сюжете и характере, но и в манере рассказа, иными словами - в репрезентативной технике, которая может варьироваться. Вообще, писатель может прибегнуть к посредству 
«рассказчика» или вести рассказ от первого лица. Во втором случае мы имеем дело с так называемым наследием фольклорной, сказовой традицией. Можно с уверенностью утверждать, что этот прием используется писателем для придания повествованию большего правдоподобия. Дж. Д. Сэлинджер широко использует этот прием, но нужно также добавить, что у Дж. Д. Сэлинджера, как, впрочем, у большинства современных писателей, этот личный, субъективный элемент все более уступает место объективному, личность рассказчика все более «изгоняется» из произведений, а при наличии диалога произведение с присущей ему краткостью формы все более приобретает драматургический характер. Автор с некоторого расстояния смотрит на события, его отношение к происходящему становится отстраненным. При этом создается иллюзия сценического действа, за которым наблюдает не зритель, а читатель. В данном случае отстраненность автора в произведениях не означает, что автору не важен контакт с читателем, совсем наоборот, писатель стремится установить контакт со своим читателем. Это стремление прослеживается и в композиции рассказов, и в их форме; повествование зачастую ведется от первого лица, эпистолярная и дневниковая запись, очень личная манера изложения, которая напоминает монолог, частые обращения к читателю - все рассчитано на установление связи с читателем. Стиль Дж. Д. Сэлинджера передает своеобразную трудность налаживания связи между людьми. Его герои, которым приходится налаживать связь с людьми, часто повторяют: «Вы понимаете меня? Вы понимаете, что я хочу сказать?» (YouknowwhatImean?). Прием повтора у Сэлинджера служит цели привлечь внимание читателя к главной мысли произведения.

Но все же основным достижением Дж. Д. Сэлинджера, по утверждению многих критиков и исследователей, является его умение «услышать» и передать живую речь американской молодежи середины пятидесятых годов. Именно живая интонация во многом определяет художественное своеобразие его произведений. Язык его героев, подростков, под стать им самим - нервный, порывистый, изобилующий сленгом и жаргоном.

Все это указывает на «разговорность» стиля героев, причем непринужденная «разговорность» стиля сэлинджеровских героев достигается путем эмоциональности, и одним из средств передачи эмоциональности речи служит эпитет. Добавим, что, стремясь показать эмоциональность речи, автор прибегает к курсиву, как бы подчеркивая интонационную неровность речи.

Анализируя рассказы Дж. Д. Сэлинджера, можно заметить, что автор не только рассказывает о событиях, но выражает свое отношение к ним. Одним из средств выражения модальности выступает эпитет.

Традиционно эпитет трактуется как лексико-синтаксическое изобразительновыразительное средство языка, выполняющее функцию определения (exposedeyes), обстоятельства (tospeaklively) или обращения (mydear!), содержащее экспрессивную характеристику предмета или явления и выражающее субъективное восприятие эмоциональнооценочного характера [Арнольд, 2012; Гальперин, 2013; Кузнец, Скребнев, 1960]. При этом И.Г. Гальперин отмечает, что эпитет является таким стилистическим средством, которое основывается на взаимодействии эмотивного и логического значения в атрибутивной фразе и используется для того, чтобы охарактеризовать объект, акцентировать внимание читателя на определенных свойствах объекта и таким образом показать индивидуальное восприятие и оценку автором этих свойств, то есть субъективность и оценочность это то, что отличает эпитет от простого логического неоценочного определения [Гальперин, 2013, с. 157]. Термин «эмотивность» в определении И. Г. Гальперина позволяет обратить особое внимание на способность воздействия эпитета на читателя с целью достижения определенного эмоционального отклика и подчеркивает способность данного стилистического средства оказывать сильное эмоциональное воздействие на читателя.

Современные авторы более склонны к фрагментарному портрету, причем этот портрет создается через отдельные замечания, штрихи, детали, то есть портрет героя со- 
здается постепенно. Прозу Сэлинджера называют отточенной и тщательно продуманной. Абстрактность ему органически чужда, в его произведениях мы можем увидеть «любование конкретным», и деталь занимает у него очень важное место. Его интересует жест, выражение лица, звук голоса. Дж. Д. Сэлинджер исследует малейшие движения души, анализирует своих героев изнутри, и этот анализ настолько прост и оригинален в своей простоте, что вероятность обнаружения чего-то подобного практически сведена к нулю.

Практически у каждого сэлинджеровского героя с самого начала есть свой прикрепленный эпитет, который становится ключевым и сопровождает данный персонаж. Сэлинджера по праву можно назвать мастером речевой детали, поскольку иногда одним только словом в речи своего героя либо в описании его внешности, поведения Сэлинджер может охарактеризовать всю его сущность. Портреты обывателей, изображаемые Дж. Д. Сэлинджером, очень ярки и выразительны даже тогда, когда они обрисованы бегло. Очень четко это можно проследить на основе рассказа «Дорогой Эсме с любовью - и всякой мерзостью» («For Esme - with Love and Sgualor»). В описании портрета Эсме сразу замечаем «blase eyes» (буквально - пресыщенные глаза, литературно - холодные, оценивающие - ... blase eyes that, I thought, might very possibly have counted the house, и далееhouse - counting eyes of hers.

Описание внешности ее брата, Чарльза, предстает перед читателем не сразу, а постепенно; и не прямо, а через его действия: He gazed back at me with immense green eyes. Charles opened his enormous eyes. He then looked at me with his exposed eyes...

Описание своего отца: He had terribly penetrating eyes, for a man who was intransically kind. Снова глаза - «ужасно проницательные». Здесь, как нам кажется, имеет место очень интересное явление - эпитет-наречие. Хотелось бы добавить, что это явление характерно для работ Дж. Д. Сэлинджера, можно с уверенностью утверждать, что оно является одной из важнейших характеристик его стиля.

Наречие в английском языке служит для выражения определенного уровня интенсивности, создавая нужное для повествования напряжение. В сочетании с эпитетом наречие образует двуступенчатый эпитет, который в художественном тексте имеет высокую меру экспрессивности и обладает ярко выраженными эмоционально-оценочными коннотациями [Любовская, 2016, с. 7]. Наречие в такой конструкции помогает регулировать степень интенсивности путем усиления или ослабления эмоциональности, оценочности и экспрессивности прилагательного или причастия: terribly penetrating, transically kind, faintly clinical, terribly prolific, terribly cold, extremely brilliant, extremely gifted, exceedingly lovable, extremely dirty, fairly unique, slightly bored, unbearably funny. Наличие большого количества эпитетов-наречий, таких как extremely, terribly, fairly, позволяет не только выражать высокую степень интенсивности признака, но и указывает на «живую», непридуманную речь, поскольку данные эпитеты-наречия свойственны, прежде всего, разговорной речи. При этом возникает большая вероятность того, что усилительные наречия, обладающие высокой степенью интенсивности в разговорной речи, постепенно теряют свое первоначальное значение качественной характеристики объекта и обозначают лишь определенную степень интенсивность свойства объекта.

Некоторые исследователи стилистических особенностей наречия отмечают, что в разговорной речи наблюдается тенденция использования безсуффиксальных наречий с целью придания речи живости и выразительности, и этот вид становится нормой литературной разговорной речи произведений американских писателей [Мороховский, 1984]. Стремление дать как можно более точную речевую характеристику герою, передать живую речь повседневной жизни определяет выбор безсуффиксальных наречий, которые выступают в качестве выразительных средств, позволяющих запечатлеть простую речь, спонтанно возникающую в процессе передачи информации. Безсуффиксальные наречия сходны по своей структуре с прилагательными, иными словами прилагательные превращаются в разговорной речи в наречия: Idoitregular. Texas sure was a great place to grow up. 
В данном случае мы видим, что слова «regular» и «sure» по своим функциональным характеристикам являются наречиями, при этом, если функциональное наречие «regular» встречается на данный момент только в разговорной речи и не закреплено в словарях, то «sure» имеет закрепленное в словаре значение наречия и употребляется в неофициальной разговорной речи [Longman, 2020]. Безсуффиксальные наречия используются в основном в прямой речи и дополняют портрет героя произведения, характеризуя его как человека недостаточно образованного с низким уровнем культурного развития [Мороховский, 1984].

В своих произведениях Сэлинджер отдает предпочтение суффиксальным наречиям, ведь его герои - люди умные, мыслящие «верно», даже если это всего лишь ребенок.

Эпитет-наречие в произведениях Дж. Д. Сэлинджера также описывает качество и оттенки действия - походки, движения, жеста, взгляда. Наглядный пример употребления автором эпитета-наречия можно увидеть в рассказе «Перед самой войной с эскимосами» («Just Before theWarwith the Eskimos»), диалог между Селиной (Selena) и Джинни (Ginnie):

"Don't I always pay half?» she asked innocently.

«No» said Ginnie flatly.

"I always bring the tennis balls, don't I? " Selena asked unpleasantly.

"All right, all right» Selena said loudly... [Salinger, 1982, c. 54].

Идалее, как реакция Селины на этот разговор - ее показная манера: Just barely leaving the cab door open, she walked briskly and obliviously, like visiting Hollywood royalty, into the building.

В рассказе «Тедди» («Teddy») также встречаются фразы, передающие оттенки действия, в частности в разговоре Тедди с Никольсоном (Nicholson) характеристика действий Никольсона: "Not personally» he said dryly; "I follow you,» Nicholson said, rather shortly; "If you'd rather not discuss this, you don't have to," Nicholson said abruptly, and rather brusquely [Salinger, 1982, с. 168]. Короткие, сухие фразы, сопровождаемые эпитетом-наречием, которые Никольсон бросает как бы на ходу, указывают прежде всего на его интерес к теме разговора и личности главного героя, чей рациональный подход к жизни резко контрастирует с эмоциональным отношением близких ему людей, родителей, ко всему, что происходит вокруг.

Другим средством усиления эпитета являются эмотивные слова, передающие степень качества или признак объекта и действия: наречия (extremely), прилагательные (enormous, hideous, immense). Например, в рассказе «Дорогой Эсме с любовью - и всякой мерзостью» («For Esme - with Love and Sgualor») девочка обращается к солдату: «I purely came over because I thought you looked extremely lonely. You have an extremely sensitive face». Она же рассказывает о своих родственниках: «I live with aunt. She's an extremely kind person. <...> Mother was an extremely intelligent person». В описании брата Чарльза (Charles) «He's extremely brilliant for his age» и отца (Father) видим также «He was an extremely gifted genius». И далее складывается впечатление, что для нее все «чрезвычайно» («еxtremely»): "I'd be extremely flattered if you'd write a story exclusively for me sometime», "Squalor. I'm extremely interested in squalor».

Также можно добавить, что для выражения эмоциональности и экспрессивности высказывания употребляется нанизывание ряда прилагательных-определений к одному существительному, при этом, согласно И.В. Арнольд, экспрессивность эпитета повышается, если он находится в постпозиции или если предмет характеризуется целой цепочкой эпитетов [1990, с. 93]. При этом особенностью подбора эпитета в группе, на наш взгляд, является стремление автора дать разностороннюю характеристику, например, в рассказе «Тедди» («Teddy»): ... an incongruously handsome, black alligator belt; a third-class leading man's speaking voice: narcissistically deep and resonant, functionally prepared.

Но иногда автор усиливает какое-нибудь одно качество при помощи синонимичных слов. Наиболее показательно это выражено в цветовом эпитете, который играет значительную роль в описании внешности героев, а также помогает нам увидеть настроение 
этих героев. В рассказе «И эти губы, и глаза зеленые» («Pretty Mouth and Green My Eyes») цветовой эпитет выносится автором в заглавие произведения, из самого произведения мы узнаем, что главный герой - gray-hairedman, «...hisgray, mostlywhite, hair». Главная героиня - девушка, цвет глаз которой «...so blue as to appear almost violet». Казалось бы, зеленые глаза в заглавии, а на протяжении всего рассказа настойчиво подчеркивается, что глаза все же синие - это непонятное, на первый взгляд, противоречие очень просто объясняет И.Л. Галинская, исходя из полисемии слова «зеленый» в санскритской литературе, где зеленый и синий - первоначально единый цвет, обозначаемый словом «нила» [Галинская, 1986, с.41]. Следовательно, никакого противопоставления нет, Сэлинджер своеобразным образом в заголовке зашифровывает посыл, который читатель пробует разгадать на протяжении всего произведения.

Характерной чертой стиля Дж. Д. Сэлинджера также являетсястремление объединить цветовую гамму с другими качествами предмета, человека: extremely dirty, white ankle-sneakers; darling blue cardigan; his eyes, which were pale brown in color, and not at all large, were slightly crossed...; a hefty girl of about thirty, in a green, yellow and lavender chiffon dress.

Метод сплошной выборки позволяет структурно выделить в рассказах Дж. Д. Сэлинджера следующие виды эпитетов:

1) простые (simple) - представляютсобойодносложныесинтаксическиеединицы, выраженныевосновномприлагательными (hostile silence, the brilliant sunlight, a lousy career, a hideous room, entire life, a memorable person, an enormous waistline, a hostile glance, an ermine coat, an enormous woman, an opaque look, blase eyes, fishy and enormous eyes, a dressy neighborhood, a lousy mess), наречиями (asked innocently, answered coolly, waited wantonly, said warmly), существительными (a career girl), причастиямикак настоящего, таки прошедшего времени (a qualified smile; all-piercing sustained scream);

2) составные (compound) - состоят из двух или более слов, которые объединены по своему значению в синтаксическое целое, обычно это сложные прилагательные: makebelieve world; condemned-looking bus; efficient-looking woman; house-counting eyes; whitehot dignity, unendowed-looking building;

3) двуступенчатые (two-step) - образуются при помощи усилительного наречия и определения или причастия и обладают высокой степенью экспрессивности: oddly radiant, extremely squalid, strangely emotional, extremely articulate, hopelessly sincere, extremely magnetic, permanently memorable, immoderately perceptive, extremely kind, extremely intelligent, extremely gifted, extremely flattered;

4) фразовые (phrase) - образуются путем соединения словосочетаний и даже целых предложений в единое целое при помощи дефиса, являются абсолютно авторским речевым средством выражения субъективной-оценочности, всегда контекстно-обусловленны, создаются для конкретной ситуации, когда автору не хватает других выразительных средств для акцентирования внимания читателя на определенном признаке: analmost-AllAmericatackle, afewdon't-tell-me-where-to-put-my-feetseconds, asome-girls-just-don't-knowwhen-to-go-homelook, hut-hope-hoop-hoopbusiness;

5) инвертированные (reversed) - обычно представляют собой два существительных объединенных структурно предлогом of с семантическим переносом значения с определяемого слова на определение, таким образом эпитет в данной конструкции становится определяемым: a theatrical brand of quietness, my word of honour, dry sense of humour, the line of duty.

Структурное распределение эпитетов показало, что в произведениях Сэлинджера преобладает простой, составной и двуступенчатые эпитеты, фразовые и инвертированные составляют небольшую долю от общего числа. Выявленное соотношение объясняется прежде всего содержательной характеристикой рассказов, в которых герои заняты повседневными делами, их общение максимально приближено к «живой» речи, в которой необходимо умение точно и просто выражать свои мысли. 
Данное стремление также объясняет употребление героями рассказов вульгаризмов («For Esme - with Love and Sgualor», "Just Before the War with the Eskimos», "Uncle Wiggily in Connecticut», «Teddy»), которые одновременно придают разговорной манере достоверность и делают речь чрезвычайно эмоциональной. Вульгаризмы представляют собой лексическое средство, характерное для неформального стиля общения, которое призвано придать уничижительную характеристику объекту и обычно выражают сильную эмоцию отчаяние, гнев, разочарование. К вульгаризмам можно отнести часто встречаемый эмфатический эпитет goddam (god-damned), который наряду с damn выступает в различных сочетаниях с существительными любого характера. Здесь и lunch, pillow, rug, place, snob, delicatessen, house, и factory, light, head, и brother, professor, life, intellectual, animal, и Leica, corpse, brains, conversation, hands и многое другое.

Степень эмоциональности обычно зависит от ситуации, контекста, поэтому и само слово goddam (damn) можно переводить по-разному: чертовски, проклятый, идиотский, чертов, дурацкий, паршивый и т.д., соответственно интенсивность эмоциональной коннотации варьируется. При этом goddam может характеризовать не только существительное, но и действие, состояние или просто употребляться как восклицание: "Goddam if Iknow» [Salinger, 57]; "GoddamrightIdo» [Salinger, 60]; "...I god damnear faint ed when I sawyouat the hospital» [Salinger, 105].

\section{Заключение}

Дж. Д. Сэлинджер умело передает речь героев, аутентическое воспроизведение разговорной речи делает необходимым наличие большого количества средств выразительности, способных передавать эмоциональность и оценочный характер действий героев и признаков предметов. Структурное и семантическое разнообразие эпитета позволяет в полной мере достичь поставленной цели. Автор применяет эпитет для выражения оценочности и своего личного отношения к предмету, человеку, явлению, действию, подчеркивает эмоциональность разговорной речи. Использование эмфатического эпитета придает героям Дж. Д. Сэлинджера еще большую достоверность и позволяет умело выразить сильные эмоции - гнев, раздражение, негодование.

Эпитет приобретает смысл в контексте атрибутивного словосочетания и представляет с определяемым словом взаимосвязанное единство. Эпитеты выражены в основном прилагательными и наречиями и могут выступать в роли качественных наречий при глаголе, что подчеркивает драматургические черты произведения. Эпитет-наречие ограничивает или усиливает эмоциональное воздействие признака предмета или действия героя. Передать повседневную речь позволяет употребление большого количества наречий, характерных для разговорной речи. При этом выбор автором традиционного суффиксального способа образования наречий, являющихся нормой разговорной разновидности литературного языка, позволяет утверждать, что герои его произведений - люди мыслящие, умные, рассуждающие, ищущие душевной гармонии, стремящиеся к познанию мира.

Новизна исследования заключается в выявлении стилистического своеобразия эпитета посредством изучения особенностей прозы Дж. Д. Сэлинджера. Данное исследование стилистических особенностей эпитета не является исчерпывающим и намечает перспективы дальнейшего изучения эпитета в произведениях Дж. Д. Сэлинджера. Уточнение феномена эпитета, его качественный и структурный анализа делают возможным проведение сопоставительного анализа перевода эпитета на русский язык. Работа позволит дополнить теоретические подходы к эпитету как выразительному средству, обогатить возможность его практического применения в современном художественном тексте.

\section{Список источников}

1. Бернацкая В.И. 1982. Дж. Сэлинджер - автор цикла о Глассах. В кн.: Сэлинджер Дж. Избранное. Сборник. М., Прогресс: 6-23. 
2. Гальперин И.Р. 2013. Стилистика английского языка (I.R. Galperin. English Stylistics). M., URSS, Либроком, $331 \mathrm{c.}$

3. Зверев А.Б. 1997. Сэлинджер: тоска по неподдельности. В кн.: Сэлинджер Дж.Д. Сочинение в двух томах. Т. 2. Харьков, «Фолио», 479 с.

4. Кузнец М.Д., Скребнев Ю.М. 1960. Стилистика английского языка. Ленинград, Государственное учебно-педагогическое издательство Министерства Просвещения РСФСР: 173 с.

5. Мороховский А.Н., Воробьёва О.П., Лихошерст Н.И. 1984. Стилистика английского языка. Киев, Вища школа, 245 с. $438 \mathrm{c}$.

6. Сэлинджер Дж. Д. 1982. Избранное. На англ. яз. Сост. Бернацкая В. И. М., Прогресс,

\section{Список литературы}

1. Арнольд И.В. 2012. Стилистика. Современный английский язык. М., Наука, 384 с.

2. Арнольд И.В. 1990. Стилистика современного английского языка. М., Просвещение, 300 с.

3. Бочкарева Н.С. 1990. Функции детского образа в американской новеллистике начала 1960-х годов. (На материале новелл Б. ван Стойка, В. Марикони, К. Маккаллярс, К. Воннегута). В кн.: Проблемы нравственности в зарубежной литературе. Межвузовский сборник научных трудов. Пермь, ПГПИ: 92-101.

4. Галинская И.Л. 1986. Загадки известных книг. М., Наука, 128 с.

5. Колесниченко А.Н. 2008. Сленг в английском и русском языках: структурносемантический, этимологический, функциональный и стилистический аспекты: на материале произведения Д. Сэлинджера «Над пропастью во ржи». Автореферат дис. ... кандидата филологических наук. Ростов-на-Дону, 27 с.

6. Липустина О.М. Щелок Т.И., Виноградова Н.Г.2019. Эмотивная лексика в романе Дж. Д. Сэдинджера «Над пропастью во ржи». Филологические науки. Вопросы теории ипрактики, 12 (4): 55-59.

7. Любимская O.M. 2018. Слово и вещь в системе поэтики молчания Дж. Д. Сэлинджера. Вестник Пермского университета. Российская и зарубежная филология, 10 (1): 117-124.

8. Любовская О.Л. 2016. Двуступенчатый эпитет в аспекте перевода: на материале перевода англоязычной художественной литературы на русский язык. Дисс. ... канд. филол. наук. Санкт-Петербург, 225 с.

9. Петренко Д.И. 2009. Роман Дж.Д. Сэлинджера «Над пропастью во ржи» и его переводы на русский язык. Под ред. проф. К.Э. Штайн. Ставрополь, Изд-во СГУ, 240 с.

10. Тютина Е.П. 2015. Функции эмоционально-оценочной лексики в произведениях Дж. Д. Сэдинджера «Девять рассказов». В кн.: Вопросы филологии и теории перевода: социокультурный аспект. Чебоксары, Чувашский государственный педагогический университет им. И.Я. Яковлева: 233-237.

11. Штайн К.Э. 2016. Язык. Языкознание. Идеология: от социализма к российскому капитализму. Ставрополь, Полиграф-сервис, 378 с.

12. Jacquette D. 2015. Salinger's World of Adolescent Disillusion. Philosophy and Literature. Johns Hopkins University Press, 39 (1A): 156-177.

13. Longman Dictionary of Contemporary English Online. 2020. April 22. Available at: https://www.ldoceonline.com/ (accessed 22.04.2020).

14. Rostami M. S. 2012. A model for the evaluation of translations: with an emphasis on the stylistic features. International Journal of Linguistics, 4 (2): 55-72.

15. Salinger J.D. 1991. Nine Stories. New York, Boston, London, Little, Brown and Company, $198 \mathrm{p}$.

\section{References}

1. Arnol'd I.V. 2012. Stilistika. Sovremenni russki yazik: uchebnik dlya vuzov [Stylistics. Modern English: textbook for universities]. Moscow, Publ. Nauka, 384 p.

2. Arnol'd I.V. 1990. Stilistika sovremennogo anglijskogo yazika [Stylistics of modern English]. M., Publ. Prosveshenie, 300 p.

3. Bochkareva N.S. 1990. Funkcii detskogo obraza v amerikanskoj novelistike nachala 1960-h godov [Functions of the child's image in American short stories of the early 1960s]. (na material novell 
B. van Stoika, V. Marikoni, K. Makkalyaris, K. Vonneguta). In: Problemi nravstvennosti v zarubezhnoi literature. Mezhvuzovskii sbornik nauchnih trudov [Problems of morality in foreign literature. Intercollegiate collection of scientific papers]. Perm', Publ. PGPI: 92-101. $\mathrm{ka}, 128 \mathrm{p}$

4. Galinskaya I.L. 1986. Zagadki izvestnih knig [Riddles of famous books]. Moscow, Publ. Nau-

5. Kolesnichenko A.N. 2008. Sleng v anglijskom I russkom yazikah: strukturno-semanticheskij, etimologicheskij, funkcionalnij I stilisticheskij aspekti: na material proizvedeniya J.Salinjera «Nad propastyu vo rzhi» [Slang in English and Russian: structural-semantic, etymological, functional and stylistic aspects: based on the work of D. Salinger «The catcher in the rye»]. Abstract dis. ...cand. philol. sciences. Rostov-on-Don, 27 p.

6. Lipustina O.M. Shchelok T.I., Vinogradova N.G. 2019. Emotive vocabulary in J. D. Salinger's novel "The catcher in the rye". Philological science. Questions of theory and practice, 12 (4): 55-59 (in Russian)

7. Lyubimskaya O.M. 2018. A Word and a Thing in the System of J. D. Salinger's Poetics of Silence. Vestnik Permskogo universiteta. Rossiyskaya i zarubezhnaya filologiya, 10 (1): 117-124 (in Russian)

8. Lyubovskaya O.L. 2016. Dvustupenchatyy epitet $\mathrm{v}$ aspekte perevoda : na materiale perevoda angloyazychnoy khudozhestvennoy literatury na russkiy yazyk [Two-step epithet in the aspect of translation: on the material of the translation of English-language fiction into Russian]. Diss. ... cand. filol. sciences. Sankt-Peterburg, $225 \mathrm{p}$.

9. Petrenko D.I. 2009. Roman J. Salingera «Nad propastyu vo rzhi» I ego perevodi na russki yazik [J. D. Salinger's novel "The catcher in the rye" and its translations into Russian]. Ed. K.E. Shtain. Stavropol, Publ. SGU, 240 p.

10. Tyutina E.P. 2015. Funkcii emocionalno-ocenochnoj leksiki v proizvedeniyah J.Salingera « 9 rasskazov» [The functions of emotional and evaluative vocabulary in the works of Dzh. D. Salinger "9 stories"]. In: Voprosi filologii I teorii perevoda: socio-kulturnij aspect [Questions of Philology and translation theory: socio-cultural aspect]. Sbornik nauchnih statej. Cheboksari, Chuvash state pedagogical University named after I.Y. Yakovlev: 233-237.

11. Shtain K.E. 2016. Yazik. Yazikoznanie. Ideologiya: ot socioliizma k rossiiskomu kapitaliz$\mathrm{mu}$ [Language. Linguistics. Ideology: from socialism to Russian capitalism]. Stavropol, Publ. Poligrafservise, $378 \mathrm{p}$.

12. Jacquette D. 2015. Salinger's World of Adolescent Disillusion. Philosophy and Literature. Johns Hopkins University Press, 39 (1A): 156-177.

13. Longman Dictionary of Contemporary English Online. 2020. April 22. Available at: https://www.ldoceonline.com/ (accessed 22.04.2020).

14. Rostami M.S. 2012. A model for the evaluation of translations: with an emphasis on the stylistic features. International Journal of Linguistics, 4 (2): 55-72. $198 \mathrm{p}$.

15. Salinger J.D. 1991. Nine Stories. New York, Boston, London, Little, Brown and Company,

\section{ИНФОРМАЦИЯ ОБ АВТОРАХ}

Войтальянова Янина Иосифовна, кандидат педагогических наук, доцент кафедры технического иностранного языка Сибирского государственного университета науки и технологий имени академика М.Ф. Решетнёва, г. Красноярск, Россия

Шелихова Светлана Викторовна, старший преподаватель кафедры технического иностранного языка Сибирского государственного университета науки и технологий им. академика М.Ф. Решетнёва, г. Красноярск, Россия

\section{INFORMATION ABOUT THE AUTHORS}

Yanina I. Voitalyanova, candidate of pedagogical Sciences, associate Professor of the Department of technical foreign language, Reshetnev Siberian State University of Science and Technology, Krasnoyarsk, Russia

Svetlana V. Shelikhova, senior teacher of the Department of technical foreign language, Reshetnev Siberian State University of Science and Technology, Krasnoyarsk, Russia 